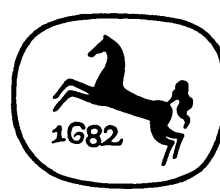

Der Ursprung des psychologischen Romans 
Josef Fürnkäs

\section{Der Ursprung des psychologischen Romans}

Karl Philipp Moritz'

"Anton Reiser»

J. B. Metzlersche Verlagsbuchhandlung 
CIP-Kurztitelaufnahme der Deutschen Bibliothek

\section{Fürnkäs, Josef}

Der Ursprung des psychologischen Romans:

Karl Philipp Moritz' "Anton Reiser «. - 1. Aufl. -

Stuttgart: Metzler, 1977.

ISBN 978-3-476-00366-9

ISBN 978-3-476-03080-1 (eBook)

DOI 10.1007/978-3-476-03080-1

(c) Springer-Verlag GmbH Deutschland 1977

Ursprünglich erschienen bei J. B. Metzlersche Verlagsbuchhandlung und Carl Ernst Poeschel Verlag GmbH in Stuttgart 1977 
Für Hans, Claudia und Philipp 
Inhalt

Einleitung: Zur Methode der Formtheorie $\ldots \ldots \ldots \ldots \ldots \ldots \ldots \ldots 1$

I. Die bürgerliche Innerlichkeit und der Roman .............6 6

1. Der ideale Roman Blanckenburgs oder die "Menschheit" des Menschen . ............................ 6

2. Der psychologische Roman als hermeneutisches Experiment oder das " Ich " als Paradox ............... 24

II. Die "Poesie des Herzens" und die "Prosa der Verhältnisse « ........................... 47

1. Die Sprache der Melancholie oder die Entordnung der Dinge $\ldots \ldots \ldots \ldots \ldots \ldots \ldots \ldots \ldots \ldots \ldots$

2. Das Subjekt als Spur oder das Milieu als Subjekt ......................... 65

3. Das "Romanhafte" und das Leben oder das Begehren und der Mangel

III. Das Kontinuum der Zeit und die erzählende Melancholie .................................. 104

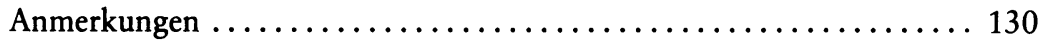

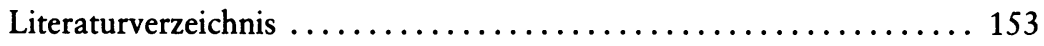




\section{Vorbemerkung}

Die vorliegende Arbeit entstand auf Anregung meiner Frau Claudia. Ihr danke ich zuerst.

Allen Marburger Freunden, insbesondere Wolff Fleischer und Rudi Wein, danke ich für die vergangene Zusammenarbeit.

Schließlich gilt mein Dank Prof. Dr. Heinz Schlaffer: er hat mir allererst den Schlüssel zu meiner eigenen Arbeit zugeeignet.

Josef Fürnkäs 